\title{
Targeting composite treatment of type 2 diabetes in middle-income countries - walking a tightrope between hyperglycaemia and the dangers of hypoglycaemia
}

\author{
J Wing, ${ }^{1,2} \mathrm{MB}$ BCh, FCP (SA); D Jivan, ${ }^{1} \mathrm{MB}$ BCh, FCP(SA), Cert Endocrinol Metab, MMed \\ ${ }^{1}$ Division of Endocrinology, Department of Internal Medicine, Faculty of Health Sciences, University of the Witwatersrand, \\ Johannesburg, South Africa \\ ${ }^{2}$ Donald Gordon Medical Centre, Johannesburg, South Africa
}

Corresponding author: D Jivan (daksha.jivan@wits.ac.za)

\begin{abstract}
Middle-income countries need a rational and cost-effective approach to optimise management of type 2 diabetes mellitus (T2DM). There is a paucity of data from such countries on the extent of hypoglycaemia and its consequences for their healthcare systems. This review provides the context for health policy change and evaluates available data on diabetes complications, focusing on hypoglycaemia in T2DM patients in non-Western countries. Suitable guidelines are suggested for these communities, which are in transition from poverty to affluence and in transition from an environment where infectious diseases predominate to one where non-communicable diseases are predominant.
\end{abstract}

S Afr Med J 2016;106(1):57-61. DOI:10.7196/SAMJ.2016.v106i1.10284

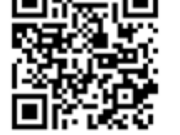

The management of type 2 diabetes mellitus (T2DM) has improved over the past decade, following the introduction of new antidiabetic agents that are able both to lower glucose levels effectively and not affect the patient's cardiovascular risk profile adversely. ${ }^{[1]}$ Some of these new therapeutic agents, the incretins, have been shown to lower traditional cardiovascular risk factors and also mitigate newly identified risk factors such as hypoglycaemia and weight gain, both of which often develop as adverse effects when tight glucose control is achieved. ${ }^{[2]}$ The WHO Multinational Study of Vascular Disease in Diabetes showed that $52 \%$ of deaths in T2DM are attributed to cardiovascular disease. ${ }^{[3]}$ Addressing both traditional and emerging cardiovascular risk factors by utilising a more composite glucose-lowering strategy may more readily achieve a comprehensive reduction in cardiovascular risk factors and a meaningful reduction in cardiovascular mortality.

While long-term prospective cardiovascular outcome studies determining cardiovascular safety and/or protection for many of the incretin agents are still awaited, there is growing evidence that these agents are likely to be more effective than traditional antidiabetic agents in reducing the many long-term and costly complications of T2DM. Importantly, incretin therapy is able to treat high and low glucose levels more physiologically and is therefore likely to address the current global unmet needs in diabetes care, especially that of composite glucose lowering. ${ }^{[4]}$

In developing countries and regions, the dual burden of infectious diseases and T2DM has increased significantly among all social classes. In South Africa (SA) between 2000 and 2009, the prevalence of T2DM in the adult population over the age of 30 years doubled, accounting for more than two million cases in 2009. ${ }^{[5]}$

In sub-Saharan Africa, the incidence of T2DM is expected to grow by more than $100 \%$ over the next decade. This will pose an unprecedented challenge to healthcare resources. ${ }^{[6]}$ If not effectively treated, the epidemic of T2DM has the potential to be as disruptive as the HIV pandemic in lowering life expectancy and reversing previous healthcare gains in Africa. ${ }^{[5-7]}$

This review focuses on the developments that have added to the available therapeutic armamentarium, and introduces data to support early rigorous but safe intervention so that the progressive adverse microvascular and in particular macrovascular complications may be reduced. This strategy is reviewed and evaluated particularly in the context of middle-income countries as defined by the World Bank. ${ }^{[8]}$

The epidemic of new cases of T2DM over the past two decades, particularly among younger patients, has resulted in a re-evaluation of clinical strategies to lower hyperglycaemia and reduce costly morbidity and mortality arising from poor glycaemic control. The first strategy involved a greater emphasis on using traditional agents (metformin, sulphonylureas and insulin) to intensify glucose control, ${ }^{[9]}$ and the second the introduction of new antidiabetic agents to improve clinical care in order to address the shortcomings of traditional agents, enable the introduction of composite treatment, promote the long-term benefits of early and aggressive glucoselowering therapy, and thereby imprint and optimise metabolic legacy in the long term.

\section{Intensive glucose control is limited by hypoglycaemia}

Four major studies ${ }^{[9-13]}$ have investigated the long-term benefits of intensive glucose control in T2DM as well as the adverse effects that can be expected from this approach (Table 1).

The landmark United Kingdom Prospective Diabetes Study (UKPDS) compared the effects of intensive blood glucose control using either sulphonylureas or insulin with conventional treatment on the risk of microvascular and macrovascular complications. ${ }^{[9]}$ The aim of the intensive intervention was to target a fasting plasma glucose (FPG) level $<6 \mathrm{mmol} / \mathrm{L}$. The conventional therapy group was treated with diet and were only given drugs if there were hyperglycaemic symptoms or FPG rose $>15 \mathrm{mmol} / \mathrm{L}$. The intensive group's overall risk of diabetes-related sequelae was reduced by $12 \%$ per annum, mainly driven by the $25 \%$ reduction in microvascular endpoints, including retinal photocoagulation. This was achieved at an increased risk of hypoglycaemia and greater weight gain than in the conventionally treated group (Table 2).

Cardiovascular events were not significantly reduced in the first 10 years of the study, but in the longer non-interventional 
Table 1. Intensive glucose control (IGC) in T2DM

\begin{tabular}{|c|c|c|c|}
\hline Study & Protocol design & $\begin{array}{l}\text { Benefits of intensive/ } \\
\text { conventional therapy }\end{array}$ & Complications \\
\hline $\mathrm{UKPDS}^{[9]}$ & $\begin{array}{l}\text { Newly diagnosed, } \\
\text { intensive } \\
\text { arms (insulin/ } \\
\text { sulphonylureas } \\
\text { and metformin) } \\
\text { v. conventional } \\
\text { therapy }\end{array}$ & $\begin{array}{l}12 \% \text { reduction in } \\
\text { diabetes-related } \\
\text { endpoints } \\
25 \% \text { reduction - } \\
\text { microvascular }\end{array}$ & $\begin{array}{l}\text { Severe hypoglycaemia ( } 2 \% / \text { year) } \\
\text { Weight gain } 2.9 \mathrm{~kg} \text { (mean) }\end{array}$ \\
\hline $\begin{array}{l}\text { UKPDS } \\
\text { (follow-up) }^{[10]}\end{array}$ & $\begin{array}{l}\text { 10-year follow-up, } \\
\text { questionnaire- } \\
\text { based, non- } \\
\text { interventional }\end{array}$ & $\begin{array}{l}13 \% \text { reduction in all- } \\
\text { cause mortality } \\
15 \% \text { reduction in } \\
\text { myocardial infarction }\end{array}$ & Not recorded \\
\hline $\mathrm{ACCORD}^{[11]}$ & $\begin{array}{l}10000 \text { patients } \\
\text { with CV risk, } \\
62 \text { years, } 20 \% \text { black } \\
\text { Median follow-up } \\
3.5 \text { years } \\
\text { Targeting <6\% in } \\
\text { intensive arm } \\
\text { Conventional } \\
-7.0-7.9 \%\end{array}$ & None & $\begin{array}{l}\text { Severe hypoglycaemia ( } 10.5 \%) \\
\text { requiring medical assistance in } \\
\text { intensive arm } \\
16.2 \% \text { requiring assistance in } \\
\text { intensive arm } \\
\text { Weight gain }>10 \mathrm{~kg} \text { in } 28 \% \text { of } \\
\text { intensively treated patients }\end{array}$ \\
\hline $\operatorname{VADT}^{[12]}$ & $\begin{array}{l}1791 \text { patients } \\
40 \% \text { CV history } \\
\text { Median follow-up } \\
5.6 \text { years } \\
\text { Insulin prescribed } \\
\text { if HbA1c not } \\
<6 \% \text { in intensive } \\
\text { arm, } 9 \% \text { in } \\
\text { conventional arm }\end{array}$ & None & $\begin{array}{l}\text { Severe hypoglycaemia } 203 / 100 \\
\text { in patient-years in IGC: } \\
52 / 100 \text { in standard therapy } \\
\text { Weight gain double in } \\
\text { intensive arm v. conventional } \\
\text { arm }\end{array}$ \\
\hline ADVANCE $^{[13]}$ & $\begin{array}{l}11140 \text { patients, } \\
\text { diabetes } \\
\text { diagnosed at } \\
>30 \text { years, average } \\
\text { duration } 8 \text { years } \\
\text { Median follow-up } \\
5 \text { years } \\
\text { IGC targeted } \\
4.4-6.1 \mathrm{mmol} / \mathrm{L} \text {, } \\
\text { conventional } \\
\text { group } \\
10-11 \mathrm{mmol} / \mathrm{L}\end{array}$ & $\begin{array}{l}\text { Reduced incidence of } \\
\text { nephropathy }\end{array}$ & $\begin{array}{l}\text { Severe hypoglycaemia } 2.7 \% \text { in } \\
\text { IGC group v. } 1.5 \% \\
\text { No weight gain }\end{array}$ \\
\hline
\end{tabular}

\section{Table 2. Principal findings from intensive glucose control (IGC)}

Early IGC induces a legacy effect of reduced microvascular and macrovascular events over subsequent
years
IGC using sulphonylureas (glibenclamide, glimepiride, gliclazide) or insulin increases severe
hypoglycaemic events two- to fourfold over conventional therapy
As the duration of type 2 diabetes increases, the rate of hypoglycaemic events increases
Hypoglycaemia is associated with increased cardiovascular mortality

questionnaire-based follow-up for a further 10 years, cardiovascular risk reduction reached significance (Fig. 1). ${ }^{[10]}$ This finding was subsequently termed the 'legacy effect' and has driven the clinical approach of early intensive treatment for
T2DM, particularly in newly diagnosed younger individuals.

The Action to Control Cardiovascular Risk in Diabetes (ACCORD) study ${ }^{[1]}$ was conducted in the USA and Canada and compared intensive glucose control with lower $\mathrm{HbAlc}$ levels $(<6 \%)$ with conventional therapy targeting HbAlc levels of $7.0-7.9 \%$. The study included 20\% African American patients and was conducted over a period of 3.5 years.

The ACCORD study identified, for the first time, the potential harm of this intensive approach in patients with multiple cardiovascular risk factors, $35 \%$ of whom had experienced a cardiovascular event prior to entry into the study. This study was halted early after increased mortality was observed in the intensively treated group of patients. Patients were treated with sulphonylureas, rosiglitazone and insulin, and a very small percentage (12.0\%) with the first available incretin mimetic, exenatide. Rates of hypoglycaemia were very high, with $10.5 \%$ of patients in the intensive therapy group experiencing severe hypoglycaemia requiring medical assistance. This was a threefold increase over the standard therapy group (3.5\%). Also weight gain was much higher in the intensively treated group, with $28 \%$ of patients gaining $>10 \mathrm{~kg}$. The absolute increase in cardiovascular mortality has been shown to be directly proportional to the frequency and severity of hypoglycaemia. ${ }^{[14,15]}$

The Veterans Affairs Diabetes Trial $(\mathrm{VADT}){ }^{[12]}$ a trial among male veterans with a mean age of 60 years and T2DM duration of 11.5 years, also treated patients with conventional agents (metformin, glimepiride, rosiglitazone and insulin) for a period of 5.6 years. There was no difference in the rate of progression of microvascular complications, development of macrovascular complications or death. There was, however, a dramatic increase in the rate of sudden death in the intensively treated group. Severe hypoglycaemia in the intensively treated group was fourfold higher than in the conventionally treated group (Table 3 ).

The Action in Diabetes and Vascular Disease-Preterax and the Diamicron modified release Controlled Evaluation (ADVANCE) ${ }^{[13]}$ trial included more than 11000 patients with T2DM diagnosed at age 30 years and older, with diabetes-related vascular disease or an additional vascular risk factor; they were observed for a mean follow-up period of 5 years. The average duration of diabetes was 8 years, lower than in VADT (11.5 years) and ACCORD (10 years). The risk of developing microvascular complications was reduced, mainly as a result of a reduction in nephropathy or worsening nephropathy. There was no impact on macrovascular events in either the 


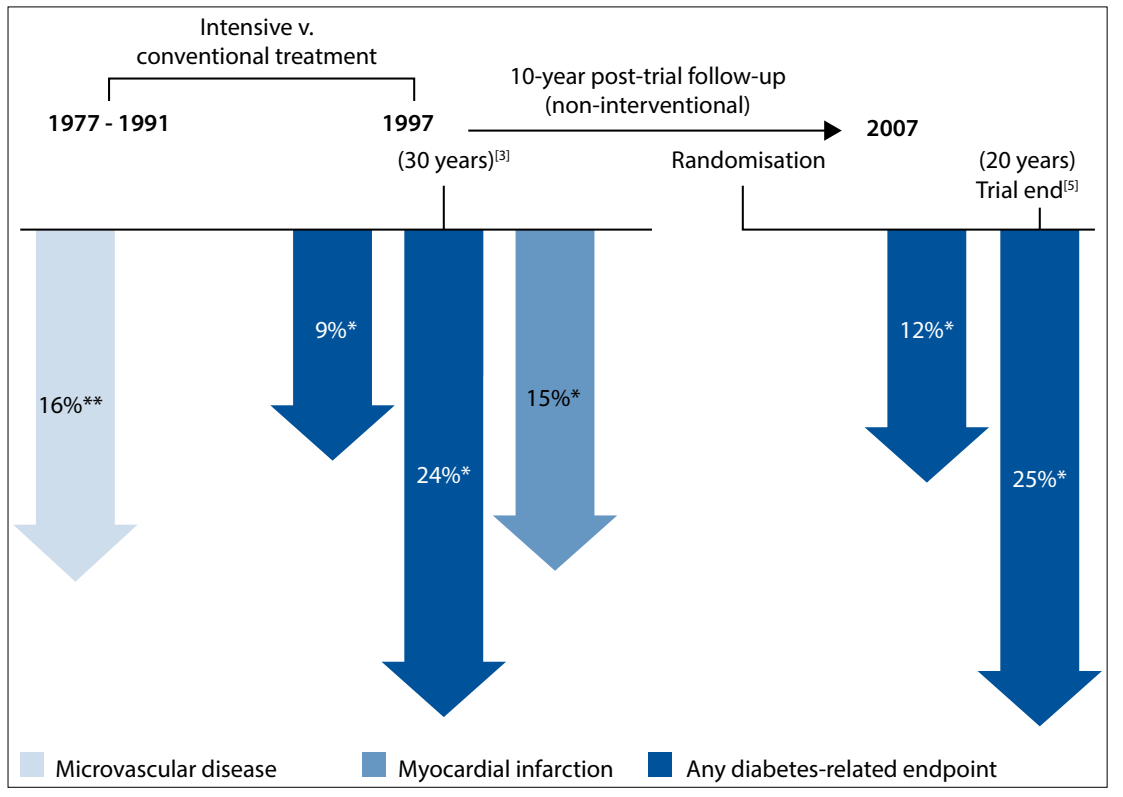

Fig. 1. Legacy effect of UKPDS study. ${ }^{[10]}\left({ }^{*} \mathrm{p}<0.05,{ }^{* *} \mathrm{p}=0.052\right.$ : intensive v. conventional treatment. $)$

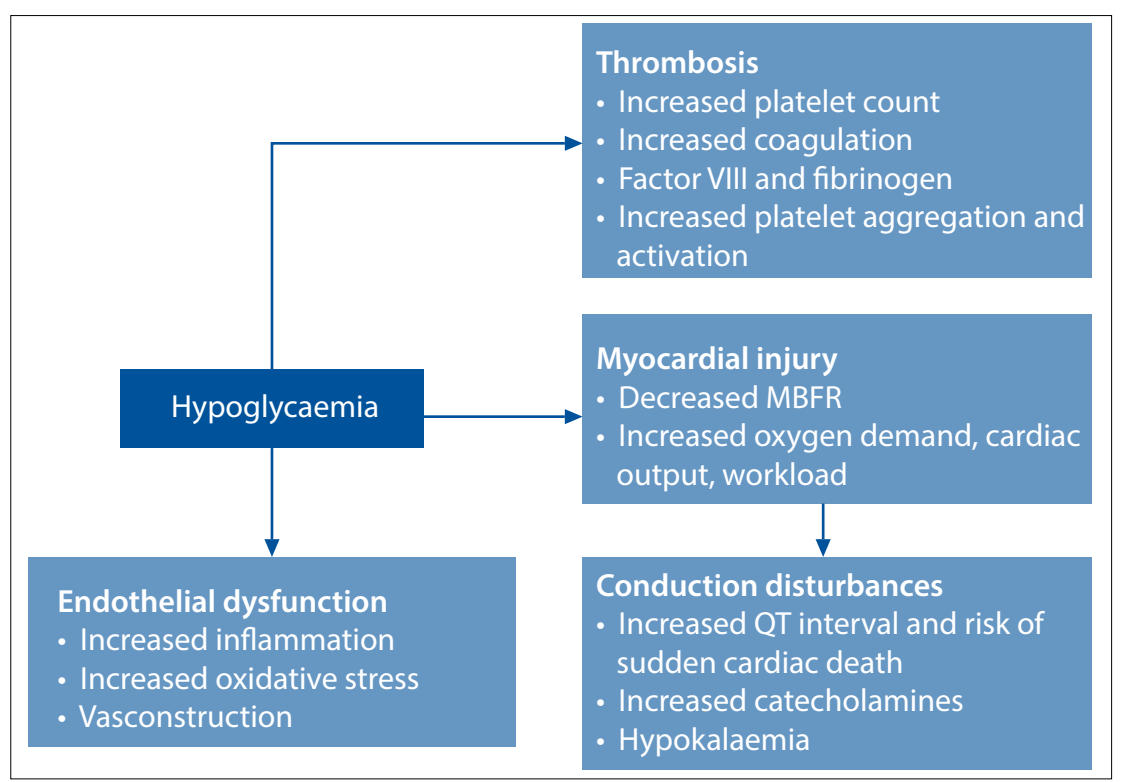

Fig. 2. Hypoglycaemia and the cardiovascular system.

\begin{tabular}{|c|c|c|}
\hline $\begin{array}{l}\text { ACCORD }^{[11]} \\
\% \text { of patients with events }\end{array}$ & $\begin{array}{l}\text { VADT }^{[12]} \\
\text { Events per } 100 \text { patient-years }\end{array}$ & $\begin{array}{l}\text { ADVANCE }{ }^{[13]} \\
\text { \% of patients with events }\end{array}$ \\
\hline Conventional 5.0 & Conventional 50 & Conventional 1.5 \\
\hline Intensive 16.2 & Intensive 200 & Intensive 2.7 \\
\hline
\end{tabular}

intensive or the conventional therapy arm. Hypoglycaemia was twofold higher in the intensive group, but overall was less frequent than in either VADT or ACCORD. There was no weight gain in the intensive arm. Severe hypoglycaemia, defined as a plasma glucose concentration of $<2.8 \mathrm{mmol} / \mathrm{L}$, was associated with a two- to threefold increase in cardiovascular mortality. ${ }^{[16]}$ Therapy did not include any incretin mimetics, but did include thiazolidinediones.

These intensive glucose control studies have shown that hypoglycaemia is an important factor in limiting the anticipated cardiovascular benefits that should accrue from tight glucose control (Table 2).

\section{Hypoglycaemia and} antidiabetic treatment

An acute hypoglycaemic event induces insulin suppression followed by the release of counterregulatory hormones, glucagon and epinephrine (acutely) and growth hormone plus cortisol (chronically). The magnitude of the counterregulatory response is attenuated and delayed with increasing age ( $>60$ years). The response in older individuals is also triggered at lower glucose levels than in the young healthy population. ${ }^{[17]}$

The counter-regulatory response in T2DM occurs at a higher threshold of glucose than in type $1 \mathrm{DM}$, allowing some degree of protection against hypoglycaemia. However, when insulin is given to improve glucose control in T2DM, the counter-regulatory response resets to a lower glucose level. The development of hypoglycaemia-associated autonomic failure also occurs in $\mathrm{T} 2 \mathrm{DM},{ }^{[18]}$ and is accompanied by a further drop in the glucose level that triggers counter-regulation. This hypoglycaemic unawareness can be partially reversed by avoiding further hypoglycaemic events. ${ }^{[19]}$

Initially, hypoglycaemia limits the achievement of target glucose control, and in particular limits attainment of longer-term cardiovascular benefit in terms of the legacy effect.

\section{Hypoglycaemia and the cardiovascular system}

Greater clarity is emerging with regard to the mechanisms underlying the deleterious effects of hypoglycaemia on the cardiovascular system, as illustrated in Fig. 2.

\section{Hypoglycaemia and cardiac ischaemia}

Studies using continuous glucose monitoring and simultaneous cardiac Holter monitoring have shown that hypoglycaemia in T2DM is more likely to be associated with cardiac ischaemia and angina symptoms than with hyperglycaemia. ${ }^{[20]}$

Even prior to the development of coronary artery disease (CAD) in T2DM, myocardial blood flow (MBF) reserve is reduced as a result of microangiopathy, which is attributed to poor glycaemic control. ${ }^{[21]}$ The baseline MBF was shown to be comparable among T2DM patients with microvascular angina, T2DM patients with $\mathrm{CAD}$ and control subjects. However, the MBF (not peak stress), measured during dipyridamole administration, was significantly lower in T2DM patients with microvascular angina than in patients with macrovascular disease. ${ }^{[22]}$

It is therefore plausible that early control of glucose in T2DM can also limit the development of coronary microangiopathy; moreover, this control should be obtained without inducing hypoglycaemia. 


\section{Hypoglycaemia and cardiac arrhythmias}

Hypoglycaemia is known to affect the electrocardiograph (ECG), resulting in lengthening of the QT interval in both type 1 and type $2 \mathrm{DM} \cdot{ }^{[23]}$

While the exact mechanism is not accurately defined, investigations using continuous interstitial glucose and ambulatory ECG monitoring are improving the understanding of the roles of hypoglycaemia-induced sympathetic neural activation, hypoglycaemia and defective counterregulation. A recent evaluation in insulin-treated T2DM using this technique has shown a greater frequency of hypoglycaemia-induced bradycardia and atrial and ventricular ectopic counts during the night ascompared with the day, and compared with periods of euglycaemia. ${ }^{[24]}$ Excessive compensatory vagal activation after the counter-regulatory phase may be responsible for the bradycardia and arrhythmias. QT prolongation only reached significance during the day in a 2014 study by Chow et al. ${ }^{[2]}$ of diabetic patients at cardiovascular risk.

Recent research on patients with long-QT syndrome due to loss-offunction mutations in KCNZQ1 has shown that these patients also have hyperinsulinaemia and symptomatic hypoglycaemia, caused by altered potassium channels in cardiomyocytes and pancreatic beta cells. ${ }^{[25]}$ This is the first identification of an extracardial phenotype in KCNZQ1 and long-QT syndrome patients. The episodes of syncope, ventricular tachyarrhythmias and cardiac arrest may also therefore be the result of hypoglycaemia and low potassium levels in these patients and not only a consequence of the genetically produced disturbance in conduction.

\section{Hypoglycaemia and thrombosis}

Acute hypoglycaemia alters platelet and clotting factors, producing a procoagulant and prothrombotic state. In a study by Dalsgaard-Nielsen et al., ${ }^{[26]}$ platelet counts were decreased significantly and activated partial thromboplastin time was also reduced during insulin-induced hypoglycaemia. Fibrinogen and factor VIII levels were substantially increased in the diabetes patients compared with healthy controls.

Overall, there was a two- to threefold increase in platelet aggregation and a 50\% increase in factor VIII concentrations in the diabetic patients.

\section{Hypoglycaemia and endothelial dysfunction}

Endothelial dysfunction is the early predictor of atherosclerosis. ${ }^{[27]}$ In diabetes, endothelial dysfunction is primarily caused by oxidative stress and increased formation of advanced glycation end-products. Oxidative stress reduces nitrous oxide bioavailability with increased free radical superoxides promoting vascular smooth-muscle cell proliferation and inflammation. Endothelin-1, the most potent vasoconstrictor of blood vessels, has also been shown to increase following hypoglycaemia. ${ }^{[28]}$ These vascular events, combined with an increase in high-sensitivity C-reactive protein and other inflammatory markers in diabetic patients experiencing hypoglycaemia, ${ }^{[29]}$ create a favourable environment for the development of atherosclerosis.

These findings are particularly important to middle-income countries with their epidemiologically younger populations, typically higher rates of complications from T2DM and inadequate resources for costly hospitalisation following adverse cardiovascular and other vascular events. There is a need to establish normoglycaemia to induce the long-term benefit of metabolic legacy. This is more readily achieved if composite therapy is available.

\section{Type 2 diabetes complications and hypoglycaemia in Africa and non- Western developing countries}

A substantially higher than expected diabetes prevalence was found among urban-dwelling black South Africans in a 2008/2009 community-based study conducted in predominantly black African areas of Cape Town compared with a similar prevalence study undertaken two decades earlier. ${ }^{[30,31]}$ The age-standardised prevalence was the highest reported in sub-Saharan Africa. Of particular importance is the finding that prevalence rose extremely sharply in people aged $>45$ years; 20 - $25 \%$ of people screened and found to be diabetic were in the younger economically active group aged 45 - 64 years. More than $50 \%$ of the diabetes cases identified were previously unknown to the participants. The high rates of impaired glucose tolerance and obesity will ensure a continuing and ever-increasing diabetes caseload for SA healthcare facilities.

Diabetes complications, including macrovascular sequelae, will be extensive in middle-income countries. In an evaluation of the nonfatal disease burden caused by T2DM in 2009 in SA, the years lost to disability (YLD) were modelled and estimated at $78900 .^{[5]}$ These included 8000 new cases of blindness, 2000 new amputations, 7000 strokes and 5500 YLD attributable to ischaemic heart disease.

A systematic review of diabetes prevalence and its complications in North Africa (Morocco, Algeria, Tunisia, Libya, Egypt, Sudan, South Sudan and Western Sahara) also highlighted that undiagnosed diabetes is common. The prevalence of complications among known and treated diabetic patients ranged from $8 \%$ to $42 \%$ for retinopathy, $21 \%$ to $22 \%$ for albuminuria, $6.7 \%$ to $46.3 \%$ for nephropathy and $21.9 \%$ to $60 \%$ for neuropathy. ${ }^{[32]}$

Data on the influence of hypoglycaemia on diabetes-related outcomes in middle-income countries are rare. There are no SA or African data. A single traceable study was found on the influence of hypoglycaemia on total mortality and cardiovascular events in a non-Western, recently developed country, Taiwan, conducted using the Taiwan National Health Insurance medical records. ${ }^{[33]}$ The study included 77661 new cases of diabetes diagnosed between 1998 and 2009. From this database, 500 patients were identified with severe hypoglycaemic events, who were hospitalised, and 1344 patients were treated for mild hypoglycaemia, on an outpatient basis. These patients were matched to a cohort of patients who did not experience hypoglycaemic events.

This real-world study showed that clinically driven hypoglycaemia increased adverse cardiovascular outcomes and hospitalisation approximately twofold. Adverse events occurred primarily in the first year that followed the hypoglycaemic event.

\section{Strategies to prevent hypoglycaemia}

Effective approaches to reduce hypoglycaemia include patient education, dietary and exercise modification, regular glucose monitoring by the patient and the use of safer glucose-lowering therapies by the clinician. ${ }^{[34]}$

\section{Medication adjustment to minimise the impact of hypoglycaemia}

The Working Group of the American Diabetes Association (ADA) and the Endocrine Society advise clinicians to substitute sulphonylureas with other classes of oral agents or with glucagon-like peptide 1 (GLP-1) analogues in patients experiencing hypoglycaemic events. In cases of frequent and recurrent hypoglycaemia, which leads to hypoglycaemic unawareness, this strategy of using oral agents that cause limited hypoglycaemia is even more important.

Incretin-based therapies, such as the GLP-1 analogues and the dipeptidyl peptidose-4 (DPP-4) inhibitors carry an overall lower risk of hypoglycaemia than the sulphonylureas and insulin and are favoured agents to minimise the extent of hypoglycaemia while still ensuring that patients reach appropriate glucose control targets. ${ }^{[3]}$ The incretins and DPP-4s appear in the Society for Endocrinology, Metabolism and Diabetes of South Africa management of diabetes guideline, ${ }^{[36]}$ and while available in the private sector are not available in the state sector owing to their cost. 


\section{Contemporary evidence-based guidelines for treatment of T2DM patients in middle-income countries and their impact on hypoglycaemic risk}

Expert guidance for the management of T2DM has been issued by many professional international bodies; examples include the ADA/ European Association for the Study of Diabetes position statement on individualised therapy ${ }^{[37]}$ and the American Association of Clinical Endocrinologists guidelines. ${ }^{[38]}$ While these developed-world guidelines provide useful guidance to best practice, developing nonWestern countries need to develop their own national guidelines as incorporation of local needs has been shown to make a substantial difference to standards of care.

A recent review of non-Western countries with identifiable national guidelines provides important insights on potential strategies for middle-income countries to avoid hypoglycaemia and improve outcomes in T2DM. ${ }^{[39]}$ Overall, 33 non-Western countries have national guideline recommendations. Many are based on recent international guidelines but do not yet incorporate their individualised therapy approach. ${ }^{[39]}$

With regard to oral antidiabetic agents, $34 \%$ of the 33 countries monitored did not provide for the preferential use of specific sulphonylureas as second-line agents, but rather made provision for the use of any second oral agent such as the thiazolidinediones, DPP-4 inhibitors or alpha-glucosidase inhibitors. Some $30 \%$ of nonWestern guidelines (12 of 33) also suggest the option of injectable GLP-1 receptor agonists as an alternative to insulin as second-line therapy.

The SA guidelines ${ }^{[40]}$ appear to follow international best practice, but still place traditional agents (metformin, sulphonylureas and insulin) in a preferred therapeutic silo. The SA positioning of newer agents (those with a minimal risk of hypoglycaemic complications or weight gain) as part of an alternative approach has reduced clinicians' ability to prescribe these agents, as their availability is restricted in the formularies of both public and private funders.

\section{Conclusion}

It is clear that hypoglycaemia is a potential independent cardiovascular risk factor in diabetes. It is also evident that good glycaemic control at the outset is important for metabolic imprinting.

Current guidelines are inappropriate for many middle-income countries in the setting of primary healthcare. This is reducing the opportunity for the least-resourced level of care to achieve tight glucose control and obtain a legacy effect, as there is only access to traditional, not-fit-for-purpose agents

There is an urgent need to review primary healthcare policy in middle-resourced countries and provide a better selection of therapeutic agents so that tight control can be achieved without the complications of hypoglycaemia. A long-term health economic study is also needed to support the expansion of these policies in resourcepoor settings.

Acknowledgement. We acknowledge the assistance of Julia Aalbers in the compilation of this article.

\section{References}

1. Monami M, Dicembrini I, Nardini C, et al. Effects of glucagon-like peptide-1 receptor agonists on cardiovascular risk: A meta-analysis of randomised clinical trials. Diabetes Obes Metab 2014;16(1):3847. [http://dx.doi.org/10.1111/dom.12175]

2. Mundil D, Cameron-Vendrig A, Husain M. GLP-1 receptor agonists: A clinical perspective on cardiovascular effects. Diab Vasc Dis Res 2012;9(2):95-108. [http://dx.doi.org/10 $1177 / 1479164112441526]$

Morrish NJ, Wang SL, Stevens LK, et al Mortality and causes of death in the WHO Multinational Study of Vascular Disease in Diabetes. Diabetologia 2001;44(Suppl 2):S14-S21. [http://dx.doi.org/10.1007/ PL00002934]
4. Drucker DJ, Nauck MA. The incretin system: Glucagon-like peptide-1 receptor agonists and dipeptidyl peptidose-4 inhibitors in type 2 diabetes. Lancet 2006;368(9548):1696-1705. [http://dx.doi. org/10.1016/S0140-6736(06)69705-5

5. Bertram MY, Jaswal AVS, van Wyk VP, et al. The non-fatal disease burden caused by type 2 diabetes in South Africa, 2009. Global Health Action 2013;6:19244 [http://dx.doi.org/10.3402/gha.v610.19244] 6. Mbanya JC, Assah FX, Saji I, et al. Obesity and type 2 diabetes in sub-Saharan Africa. Curr Diab Rep 2014;14(7):501-505. [http://dx.doi.org/10.1007/s11892-014-0501-5]

Hall V, Thomsen RW, Henriksen O. Diabetes in sub-Saharan Africa 1999-2011: Epidemiology and . Hall V, Thomsen RW, Henriksen O. Diabetes in sub-Saharan Africa 1999-2011: Epidemiology and
public health implications: A systematic review. BMC Public Health 2011;11:561-564. [http://dx.doi. org/10.1186/1471-2458-11-564]

8. World Bank. List of middle-income countries. www.data.worldbank.org (accessed $\mathrm{xxx}$ ).

9. UKPDS Group. Intensive blood-glucose control with sulphonylureas or insulin compared with conventional treatment and risk of complications in patients with type 2 diabetes (UKPDS 33). Lancet 1998;352(9131):837-853. [http://dx.doi.org/10.1016/S0140-6736(98)07019-6]

10. Holman RR, Paul SK, Bethel MA, et al. 10-year follow-up of intensive glucose control in type 2 diabetes. N Engl J Med 2008;359(15):1577-1589. [http://dx.doi.org/10.1056/NEJMoa0806470]

11. ACCORD Study Group: Gerstein HC, Miller ME, Genuth S, et al. Long-term effects of intensive glucose lowering on cardiovascular outcomes. N Engl J Med 2011;364(9):818-828. [http://dx.doi. org/10.1056/NEJMoa1006524]

12. Duckworth W, Abraira C, Moritz T, et al. Glucose control and vascular complications in veterans with type 2 diabetes. N Engl J Med 2009;360(2):129-139. [http://dx.doi.org/10.1056/NEJMoa0808431]

13. ADVANCE Collaborative Group. Intensive blood glucose control and vascular outcomes in patients with type 2 diabetes. N Engl J Med 2008;358(4):2545-2559. [http://dx.doi.org10.1056/ NEJMoa0802987

14. Gerstein HC, Miller ME, Byington RP, et al. Effects of intensive glucose lowering in type 2 diabetes. N Engl J Med 2008;358(24):2545-2559. [http://dx.doi.org/10.1056/NEJMoa0802743]

15. Bonds DE, Miller ME, Bergenstal RM, et al. The association between symptomatic, severe hypoglycaemia and mortality in type 2 diabetes: Retrospective epidemiological analysis of the ACCORD study. BMJ 2010;340:b4909 [http://dx.doi.org/10.1136/bmjb4909]

16. Zoungas S, Patel A, Chalmers J, et al. Severe hypoglycaemia and risks of vascular events and death. N Engl J Med 2010;363(15):1410-1418. [http://dx.doi.org/10.1056/NEJMoa1003795]

17. Zammitt NN, Frier BM. Hypoglycemia in type 2 diabetes. Diabetes Care 2005; 28(12):2948-2961. [http://dx.doi.org/10.2337/diacare.28.12.2948]

18. Segel SA, Paramore DA, Cryer PE. Hypoglycaemia-associated autonomic failure in advanced type 2 diabetes. Diabetes 2002;51(3):724-733. [http://dx.doi.org/10.2337/diabetes.51.3.724]

19. Fanelli C, Pampanelli S, Epifano L, et al. Long-term recovery from unawareness, deficient Fanelli C, Pampanelli S, Epifano L, et al. Long-term recovery from unawareness, deficient
counterregulation and lack of cognitive dysfunction during hypoglycaemia, following institution of rational, intensive insulin therapy in IDDM. Diabetologia 1994;37(12):1265-1276. [http://dx.doi. org/10.1007/BF00399801]

20. Descuza C, Salazar H, Cheong B, et al. Association of hypoglycaemia and cardiac ischaemia: A study based on continuous monitoring. Diabetes Care 2003;26(5):1485-1489. [http://dx.doi.org/10.2337/ diacare.26.5.1485]

21. Yokoyama I, Momomura S, Ohtake T, et al. Reduced myocardial flow reserve in non-insulin dependent diabetes mellitus. J Am Coll Cardiol 1997;30(6):1472-1477. [http://dx.doi.org/10.1016/S07351097(97)00327-6]

22. Yokoyama I, Yonekura K, Ohtake T, et al. Coronary microangiopathy in type 2 diabetic patients: Relation to glycaemic control, sex and microvascular angina rather than to coronary artery disease. J Nucl Med 2000;41:978-985.

23. Marques JL, George E, Peacey SR, et al. Altered ventricular repolarization during hypoglycaemia in patients with diabetes. Diabetes Med 1997;14:648-654.

24. Chow E, Bernjak A, Williams S, et al. Risk of cardiac arrhythmias during hypoglycaemia in patients with type 2 diabetes and cardiovascular risk. Diabetes 2014;63(5):1738-1747. [http://dx.doi. org/10.2337/db13-0468

25. Torekov SS, Iepsen E, Christiansen M. KCNQ1 long QT syndrome patients have hyperinsulinaemia and symptomatic hypoglycaemia. Diabetes 2014;63(4):1315-1325. [http://dx.doi.org/10.2337/db13$1454]$

26. Dalsgaard-Nielsen J, Madsbad S, Hilsted J. Changes in platelet function, blood coagulation and fibrinolysis during insulin-induced hypoglycaemia in juvenile diabetics and normal subjects. Thromb Haemost 1982;47(3):254-258.

27. Mudau M, Genis A, Lochner A, Strijdom H. Endothelial dysfunction: The early predictor of atherosclerosis. Cardiovasc J Afr 2012;23(4):222-231. [http://dx.doi.org/10.5830/CVJA-2011-068

28. Wright RJ, MacLeod KM, Perros P, et al. Plasma endothelin response to acute hypoglycaemia in adults with type 1 diabetes. Diabetic Med 2007;24(9):1039-1042. [http://dx.doi.org/10.1111/j.14645491.2007.02199.x]

29. Wright RJ, Newby DE, Striling D, et al. Effects of acute insulin-induced hypoglycaemia on indices of inflammation. Diabetes Care 2010;33(7):1591-1597. [http://dx.doi.org/doi: 10.2337/dc10-0013]

30. Peer N, Steyn K, Lombard C, et al. Rising diabetes prevalence among urban-dwelling black South Africans. PLoS One 2012;7(9):e43336. [http://dx.doi.org/10.1371/journal.pone.0043336]

31. Levitt NS, Katzenellenbogen JM, Bradshaw D, et al. The prevalence and identification of risk factors for NIDDM in urban Africans in Cape Town, South Africa. Diabetes Care 1993;16(4):601-607.

32. Bos M, Agyemang C. Prevalence and complications of diabetes mellitus in Northern Africa: A systemic review. BMC Public Health 2013;13:387. [http://dx.doi.org/10.1186/1471-2458-13-387]

33. Hsu PF, Sung SH, Cheng HM, et al. Association of clinical symptomatic hypoglycaemia with cardiovascular events and total mortality in type 2 diabetes. Diabetes Care 2013;36(4):894-900. [http:// dx.doi.org/10.2337/dc12-0916

34. Seaquist ER, Anderson J, Childs B, et al. Hypoglycaemia and diabetes: A report of a workgroup of the American Diabetes Association and the Endocrine Society. Diabetes Care; 2013;36(5):1384-1395. [http://dx.doi.org/10.2337/dc12-2480]

35. Noh RM, Graveling AJ, Frier BM. Medically minimising the impact of hypoglycaemia in type 2 diabetes: A review. Expert Opin Pharmacother 2011;12(14):2161-2175. [http://dx.doi.org/10.1517/1 4656566.2011.589835]

36. Society for Endocrinology, Metabolism and Diabetes of South Africa. SEMDSA guidelines for the diagnosis and management of type 2 diabetes mellitus for primary health care. South African Family Practice 2010;52(6):507-511. [http://dx.doi.org/10.1080/20786204.2010.10874035]

37. Inzucchi SE, Bergenstal RM, Buse JB. Management of hyperglycaemia in type 2 diabetes: A patientcentred approach: Position statement of the American Diabetes Association (ADA) and the European Association for the Study of Diabetes (EASD). Diabetes Care 2012;35(6):1364-1379. [http://dx.doi. $\mathrm{org} / 10.2337 / \mathrm{dc12}-0413]$

38. Garber AF, Abrahamson MJ, Barzilay JL, et al. AACE comprehensive diabetes management algorithm 2013. Endocrinol Pract 2013;19(2):327-336. [http://dx.doi.org/10.4158/endp.19.2.a38267720403k242]

39. Home P, Haddad J, Latif ZA, et al. Comparison of national/regional diabetes guidelines for the management of blood glucose control in non-Western countries. Diabetes Ther 2013;4(1):91-102. [http://dx.doi.org/10.1007/s13300-013-0022-2]

40. The 2012 SEMDSA guideline for the management of type 2 diabetes (Revised). JEMDSA 2012:17(2):S1S95. http://www.jemdsa.co.za/index.php/JEMDSA/article/view/329 (accessed 25 November 2015).

Accepted 9 November 2015 